\title{
Perbandingan Framework Untuk Pengembangan Aplikasi Web Object Oriented Programming Menggunakan Moose
}

\author{
Triana Wulandari $^{1}$, Endra Prasetya Rudiyanto ${ }^{2}$, Mikhael Manda Pasaribu ${ }^{3}$ \\ ${ }^{1,}$ Universitas Nasional Pasim, Indonesia \\ ${ }^{2,3}$ STIMIK Likmi, Indonesia \\ Email authors: ${ }^{1}$ eclipse.prasetya@gmail.com, ${ }^{2}$ aprast8283@gmail.com, \\ mandaskill@gmail.com
}

\begin{abstract}
ABSTRAK
Semakin berkembangnya bahasa pemrograman saat ini membuat banyak pilihan bahasa dan fitur yang dapat dimanfaat oleh programmer untuk mempercepat pekerjaan membuat sebuah perangkat lunak. Salah satu perkembangan yang sangat dirasakan manfaatnya adalah framework. Dalam pemrograman, framework sangat berguna untuk membantu dalam mendesain logika dan alur program. Untuk beberapa program yang akan selalu digunakan maka kita dapat menggunakan fasilitas yang dimiliki framework. Dalam pelaksanaannya framework bergantung dari kebiasaanprogrammer dan output user yang diinginkan. Jika berbasis web maka kita dapat menggunakan fraework web, jika berbasis mobile maka dapat menggunakan framework mobile. Pada penelitian kali ini kita akan membandingkan sejauh mana keunggulan dari masing - masingframework dengan menggunakan metode moose yang dikhususkan untuk object oriented programming. Sehingga nantinya kita dapat melakukan pilihan yang tepat sesuai dengan kebutuhan kebutuhan user dalam pengembangan perangkat lunak.
\end{abstract}

Kata Kunci : framework, moose, programming

\section{ABSTRACT}

The development of programming languages today makes many choices of languages and features that can be used by programmers to speed up the work of making software. One of the most useful developments is the framework. In programming, frameworks are very useful to assist in designing logic and program flow. For some programs that will always be used, we can use the facilities owned by the framework. In its implementation the framework depends on the habits of the programmer and the desired user output. If it is web-based then we can use a web framework, if it is mobile-based then we can use a mobile framework. In this study, we will compare the advantages of each framework using the Moose method which is devoted to object oriented programming. So that later we can make the right choice according to the needs of users in software development.

Keyword : Framework, moose, programming

\section{PENDAHULUAN}

Pada era pembuatan digital transformasi saat ini banyak hal yang menggunakan bantuan aplikasi untuk memudahkan proses otomatisasi. Pembuatan aplikasi yang sangat dinamis dan cepat membutuhkan bantuan beberapa kerangka kerja atau biasa kita kenal dengan framework. Framework ini membantu kita dalam hal organisasi direktori dan skrip program, 
mempersingkat pekerjaan kita karena beberapa fitur standar sudah disediakan dengan baik. Proses validasi pelemparan data dibukukan dengan baik oleh framework.

Seiring dengan banyaknya pemakai framework dan kebutuhan pengguna yang bervariasi membuat beberapa komunitas dan perusahaan mengembangkan framework secara berkelanjutan. Menambahkan fitur-fitur yang membantu mempercepat pembuatan aplikasi dengan framework tersebut. Ada framework yang diperuntukkan untuk web-based aplikasi, ada juga framework yang khusus dikembangkan untuk mobile aplikasi.

Semakin beragamnya framework, semakin membuat beberapa perusahaan dan pengembang aplikasi merasa kebingungan memilih yang terbaik. Oleh karena itu untuk dapat memilih framework mana yang tepat untuk kita terapkan pada unit bisnis perusahaan membutuhkan pertimbangan dan pemikiran yang mendalam. Tidak hanya berkaca pada kemudahaan pengembangan aplikasi, tapi pemilihan framework juga dilihat dari kebutuhan aplikasi kedepan, support system yang diberikan oleh framework tersebut, keamanan framework tersebut sampai dengan continual improvement yang dibangun oleh framework tersebut. Keberadaan sumber daya manusia yang handal dan kemampuan financial perusahaan juga dapat dijadikan dasar pemilihan sebuah framework. Oleh karena itu kajian kali ini akan membahas tentang apa kelebihan dan kelemahan framework tersebut. Sehingga diharapkan nantinya perusahan dan tim IT dapat memutuskan secara objective sesuai dengan kebutuhan mendasar pengembangan sistem yang mengacu pada kondisi sumber daya manusia dan aplikasi saat ini.

\section{METODE PENELITIAN}

Kajian perbandingan framework kali ini menggunakan dua cara untuk mendapatkan gambaran seperti apa sebenarnya kelebihan, fitur-fitur serta beberapa factor peniliain lainnya yang dimiliki oleh framework yang akan dikaji dan dianalisa. Kedua metodologi tersebut dipaparkan sebagai berikut.

\section{Literasi}

Metode pertama yang kita gunakan mengacu kepada literasi yang dimiliki oleh masing-masing framework. Diambil dari setiap dokumentasi resmi masing-masing framework sehingga kita memiliki gambaran secara menyeluruh tentang framework yang sedang kita kaji. Selain dari dokumen resmi framework, kita juga menggunakan beberapa referensi beberapa forum dari masing-masing framework.

\section{Source Code Library}

Metoda kedua yang digunakan ini dengan membandingkan source code program yang dimiliki oleh masing-masing framework secara objective sebagai programmer. Dengan mengetahui skrip kode yang dimiliki kita memahami dan menelaah seperti apa alur dan disain framework tersebut dibuat. Sehingga kita paham apa tujuan framework tersebut dibuat.

\section{Moose}

Skema metode moose adalah skema motoda yang menggunakan sembilan faktor utama pengukuran. Adapun skema metode kajian dapat dilihat pada gambar dibawah ini. Moose membandingkan faktor $\mathrm{x}$ dalam hal ini framework dengan sembilan komponen utama atau disebut faktor y dalam mengevaluasi dan membandingkan sebuah perangkat lunak. Kesembilan komponen tersebut merupakan faktor yang biasa dipakai oleh pengguna dalam melakukan proses uji kelayakan. 


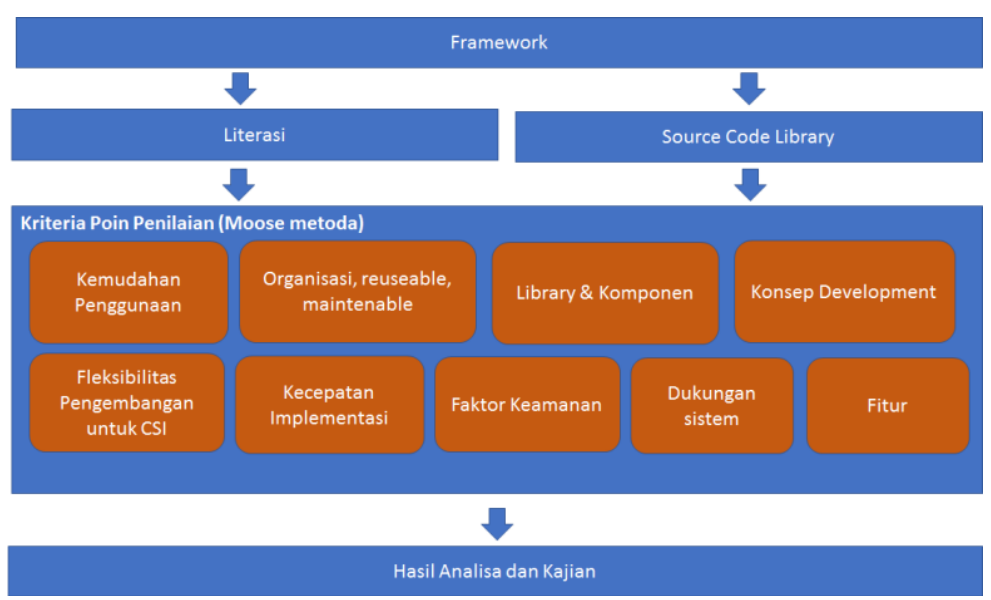

Gambar 1. Moose Metodologi

Kesembilan faktor tersebut adalah:

1. Kemudahan Penggunaan

2. Organisasi penggunaan, reusable

3. Kelengkapan Komponen Library

4. Fleksibilitas

5. Konsep Pengembangan

6. Keceatan implementasi dan development

7. Support Development

8. Fitur dan,

9. Keamanan

\section{HASIL DAN PEMBAHASAN}

Framework yang dikaji untuk penelitian ini adalah PHP CI, PHP Laravel, SpringMVC, Django Python,.Net Core,Anglar, React, Vue dan Flutter. Framework tersebut diperuntukkan untuk pengembangan aplikasi berbasis web namun ada satu framework flutter yang diguankan untuk mobile development aplikasi. Hasil Kajian berdasarkan Sembilan batasan digambarkan dengan grafik dibawah ini dengan mengelompokkan sesuai dengan metode moose parameter adalah sebagai berikut.

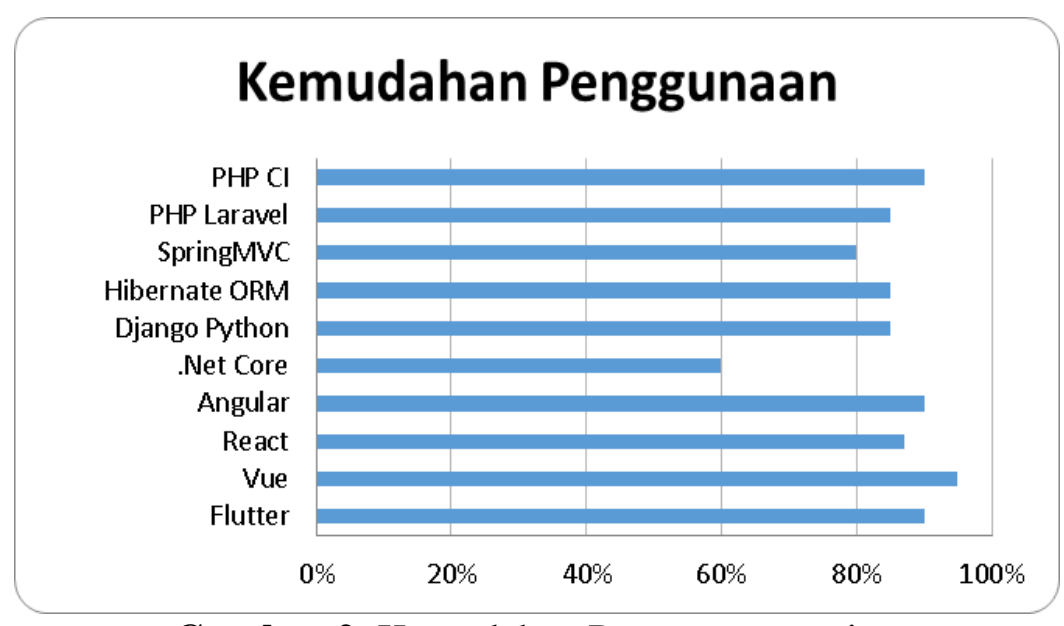

Gambar 2. Kemudahan Penggunaan rating 


\section{Organisasi Penggunaan, reusable,maintenable $10-100 \%$}

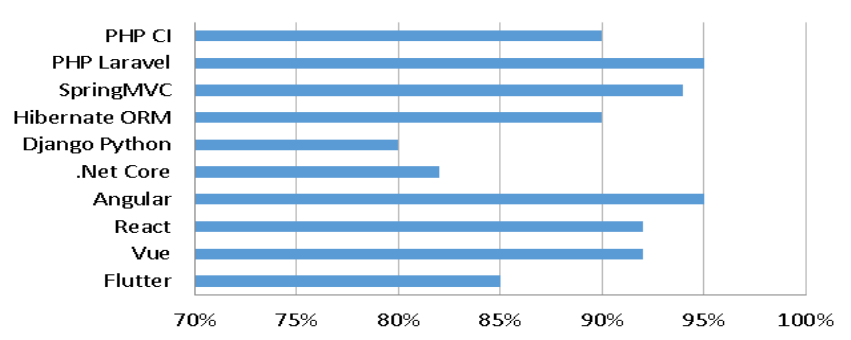

Gambar 3. Organisasi,Penggunaan, reusable dan manintenable rating.

\section{Kelengkapan Komponen dan library}

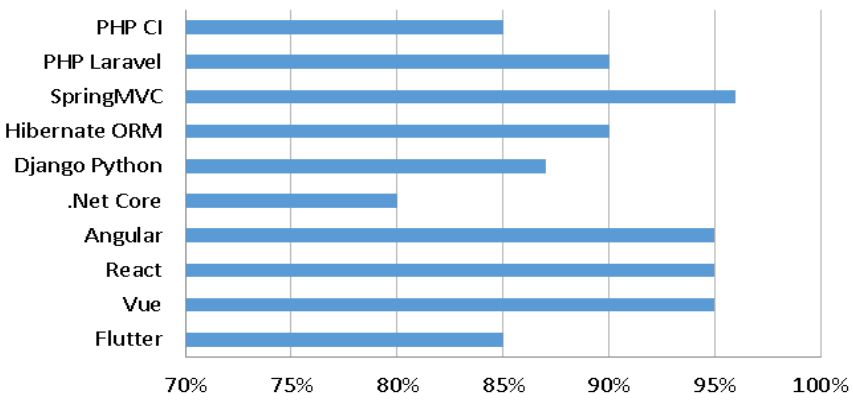

Gambar 4. Kelengkapan Komponen dan library

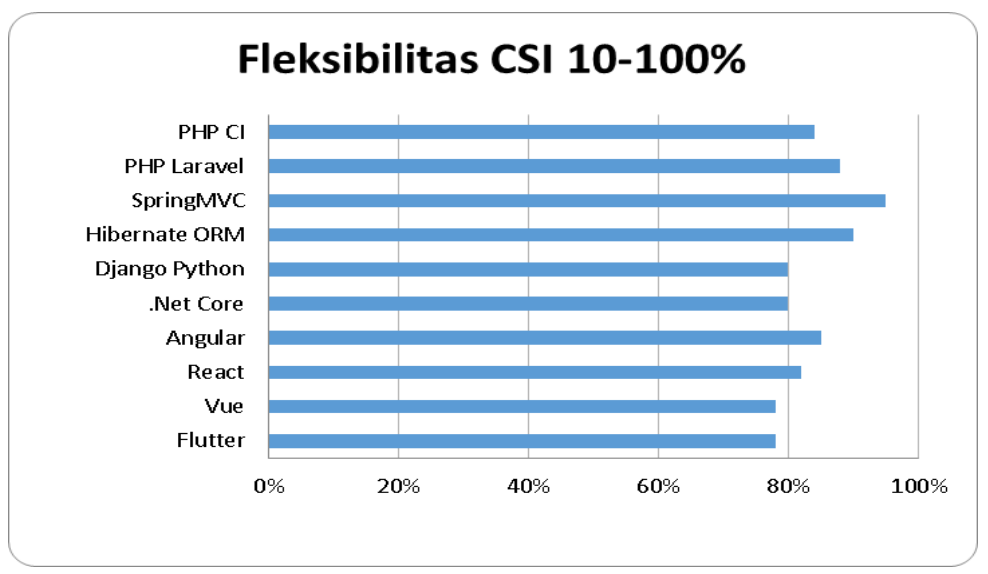

Gambar 5. Fleksibilitas Continual Service Improvement 


\section{Konsep pengembangan $10-100 \%$}

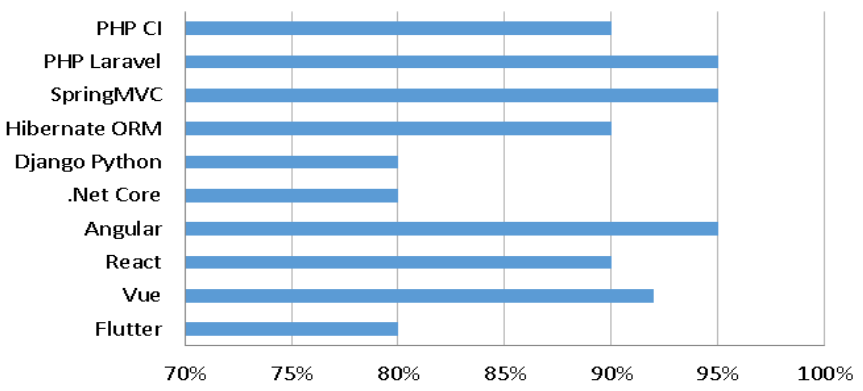

Gambar 6. Konsep Pengembangan

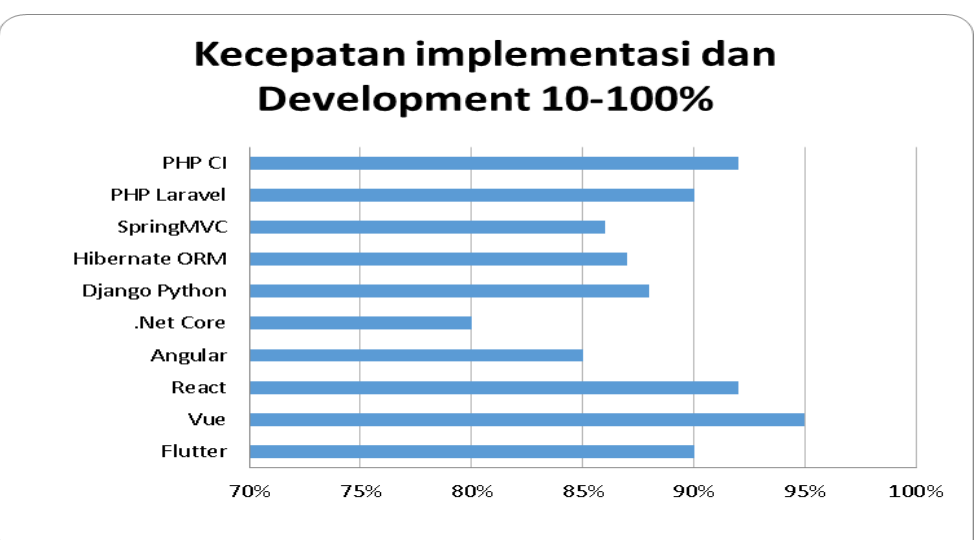

Gambar 7. Kecepatan Implemetasi dan Development.

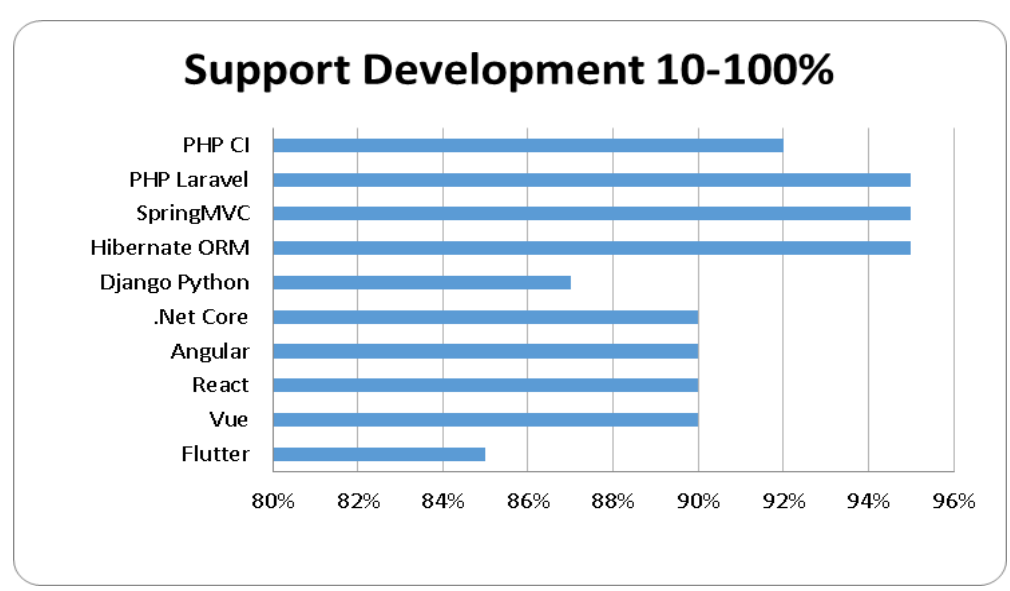

Gambar 8. Support Development 


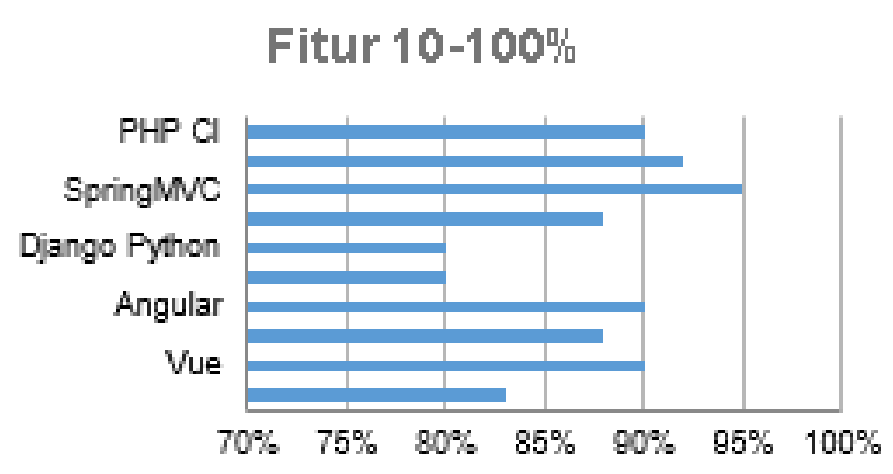

Gambar 9. Fitur

\section{Faktor Keamanan 10-100\%}

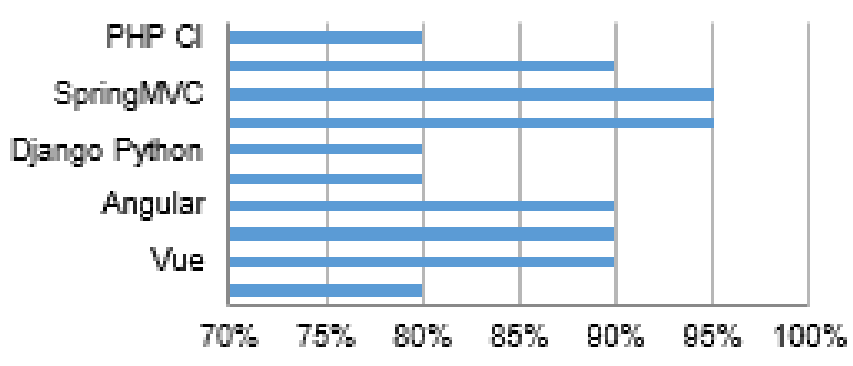

Gambar 10. Faktor Keamanan

\section{KESIMPULAN}

Dari hasil analisa kesepuluh framework yang diteliti didapati bahwa terdapat 2 kelompok framework yang dapat kita jadikan acuan yaitu:

1. Framework fullstack aplikasi

2. Framework frontend

Untuk fullstack framework maka saat ini yang dapat diandalkan dari sisi pengembangan masa depan adalah PHP Laravel. Karena pada PHP Laravel banyak ditemukan kelebihan dan dukungan yang cukup banyak dari forum pengembangnya. Sedangkan untuk frontend framework yang masih stabil dan banyak diimplementasikan adalah angularjs yang kedepannya akan banyak perbaruan library dalam sisi pengembangan dan kolaborasi dengan bahasa yang lain.

Dari hasil analisis ini, maka jika akan melakukan penelitian ini lebih lanjut dikemudian hari maka disarankan untuk menambahkan faktor pengukuran pada moose dari sisi auto scaling dan microservice programming. Karena pada pada mendatang pemrograman yang bersifat kontainer akan banyak digunakan sehingga setiap framework harus mendukung hal tersebut untuk dapat berkembang dan bertahan lebih lama. 


\section{DAFTAR PUSTAKA}

Dipetik November 15, 2020, dari https://en.wikipedia.org/wiki/List_of_.NET_libraries_and_frameworks

Bencmark, W. F. (2020, Mei 28). Techno. Diambil kembali dari https://www.techempower.com/benchmarks/\#hw=ph\&test=plaintext

Catalog, .. C. (2020). microsoft.com. Diambil kembali dari https://docs.microsoft.com/enus/dotnet/core/rid-catalog

Code Ogniter Documentation. (2020, November). Diambil kembali dari https://codeigniter.com/user_guide/intro/index.html

Dependency injection into controllers in ASP.NET Core. (2019, desember 11). Dipetik November 10, 2020, dari https://docs.microsoft.com/enus/aspnet/core/mvc/controllers/dependency-injection?view=aspnetcore-5.0

Microsoft.com. (2020, November 8). What is Visual Studio Codespaces? Diambil kembali dari microsft.com: https://docs.microsoft.com/enus/visualstudio/codespaces/overview/what-is-vsonline

net/core, d. (2020, july 1). Diambil kembali dari https://github.com/dotnet/core/blob/master/oslifecycle-policy.md

Only), J. C. (2020). JBoss Community Archive (Read Only). Dipetik November 10, 2020, dari https://hibernate.atlassian.net/browse/HHH

Overview of .NET source code analysis. (2020, Oktober17). Diambil kembali dari https://docs.microsoft.com/en-us/dotnet/fundamentals/code-analysis/overview

Package, D. (t.thn.). Dipetik November 10, 2020, dari The Django source code repository

Process, M. E. (2020, january 4). microsoft.com. Dipetik November 9, 2020, dari https://docs.microsoft.com/en-us/dotnet/standard/managed-execution-process

Project, D. (2010). Dipetik 2020, dari https://djangopackages.org/

Project, H. (2019, November 5). Dipetik November 12, 2020, dari https://community.jboss.org/en/hibernate

Spring. (2020, January 2). Vmware. Dipetik November 2020, 2020, dari https://spring.io/projects.

Starter, C. a. (2020, maret 3). microsoft.com. Dipetik November 9, 2020, dari https://docs.microsoft.com/en-us/azure/devops-project/azure-devops-project-aspnetcore

Susanti, I., Syairozi, M. I., \& Lukman, H. Y. W. (2021). Analisis Sistem Manajemen Dalam Pengelolaan Bumdes Di Desa Bluluk. Jurnal Sains Sosio Humaniora, 5(2), 701-710.

Syairozi, M. I. (2017). Percepatan Pengurangan Kemiskinan Sektor Pertanian di Kabupaten Malang. In Seminar Nasional \& Call For Paper, FEB Unikama (pp. 145-155).

The Python Package Index (PyPI) is a repository of software for the Python programming language. (2020). Dipetik November 2020, dari https://pypi.org/

The Python SQL Toolkit and Object Relational Mapper. (2020). Diambil kembali dari https://www.sqlalchemy.org/

What diagnostic tools are available in .NET Core? (2020, november 8). Diambil kembali dari https://docs.microsoft.com/en-us/dotnet/core/diagnostics/

Wijaya, K., \& Syairozi, M. I. (2020). Analisis perpindahan tenaga kerja informal Kabupaten Pasuruan. Jurnal Paradigma Ekonomika, 15(2), 173-182. 